\title{
AOR
}

Selected Papers of \#AolR2018: The $19^{\text {th }}$ Annual Conference of the Association of Internet Researchers Montréal, Canada / 10-13 October 2018

\section{'DEEP-FRIED’ AND DENATURALIZED: CRITIQUING MEMETIC META- ONTOLOGIES}

\author{
Saskia Kowalchuk \\ Concordia University
}

\section{Background}

This essay offers a theoretical and critical approach to the practice of Internet meme making, popularly referred to as 'deep-frying', which involves the degradation of visual quality and linguistic comprehensibility for the purposes of humor. The paper is primarily focused on the ways in which these memes can be called upon to subvert ontological and material norms of existing memetic communications. The significance of these practices lies in a coherent understanding of 'memeing', and 'deep-fried memeing', as a collective artistic phenomenon that circumvents national boundaries and is bound up in the shared experience of cooperative image reappropriation.

Hito Steryl's notion of 'poor images' provides an ideal conceptual framework for the potentially disruptive quality of memes. These low-resolution reproductions circulate through non-sanctioned channels, standing in direct opposition to the fetishization of rich images in the state sponsored image making hegemony (Steryl, 2012). Poor images are unmoored from their original context and are re-imagined with every reproduction, connecting global communities of illicit creativity; forming what filmmaker Dziga Vertov referred to as 'visual bonds' (Steryl, 2012). In this way, a deep-fried meme can be thought of as a poor image brought to its logical extreme. Purposely degraded and recontextualized, the deep-fried meme exists to defamiliarize practices of networked engagement and re-mystify the processes of reading and creating memes.

Fundamentally, the successful deployment of memetic humor relies on a thoughtful adherence to established generic conventions with a creative and unexpected twist (Shifman, 2015; Milner, 2016; Phillips and Milner, 2017). These conventions are upheld by the communities of consumption who enforce quiddity and quality, forming an 'ingroup' of those who can read and create memes within the given parameters (Miltner, 2014). Deep-fried memes, however, seek to complicate this phenomenon by breaking

Suggested Citation (APA): Kowalchuk, S. (2018, October 10-13 'Deep-Fried' And Denaturalized: Critiquing Memetic Meta-Ontologies. Paper presented at AolR 2018: The $19^{\text {th }}$ Annual Conference of the Association of Internet Researchers. Montréal, Canada: AolR. Retrieved from http://spir.aoir.org. 
with generic convention so dramatically and frenetically that the images produced bear little or no resemblance to their source imagery and associated in-groups. In doing so deep-fried memes can bring users together from a place of mutual alienation, demonstrating an uncanny awareness of the existing tensions of memetic production and consumption.

\section{Methodology \& Analysis}

As a starting point for this formal analysis, I began by assembling a corpus of 150 memetic images that demonstrated the quiddity of deep-fry. By doing so I identified necessary formal requirements that qualify the present parameters of deep-fry practices. These include, saturated coloration; increased grain; lowered resolution or increased compression; warping or bubbling effects; unnecessary lens flaring; excessive emoji usage; and linguistic misdirection or formulaic subversion. The corpus included 56 selections from Tumblr, 54 selections from Instagram, and 39 examples from Reddit, all of which demonstrate two or more of the aforementioned qualities.

I have subsequently explored three primary layers on which these techniques operate, to produce an ontological meta-critique. The first resides at the level of the message, both linguistic and iconic, as per Barthes. In the essay, I examine the joint degradation of visual clarity and linguistic comprehensibility through multi-paneled memes, elucidated by the increasing formalization of the pronoun 'who', that produce a relay function (Barthes, 1977). This relay function suggests the creators' awareness of the prevailing discourses surrounding digital communications and the ostensible impoverishing of visual and linguistic quality. Crucially, this self-awareness is the driving force of the deep-fried meme; users are swept up in the tide of teleological acceleration but can still have fun on the ride.

The second and third levels of analysis that I undertook relate to the tenants of Information Theory, through which I identified two major memetic defamiliarizing practices in noise introduction and redundancy augmentation. Following Rosa Menkman, I conceived of deep-fried memes as noise artifacts; objects that radically exploit their failure to disappear as techné and therefore confront embedded teleological anxieties (2011, p.14). As such, noise is introduced with the visual effects that give deep-fried memes their name and through breaking with formal linguistic requirements of memetic humor. The memes I chose to analyze exemplify the "BOTTOM TEXT" trend in deep-fried. This technique relies on a reader's familiarity with the traditional set up/punchline format of a top text-bottom text meme. Rather than providing the payoff, the author replaces it with the "BOTTOM TEXT" placeholder present while making a meme using an online generator. This is highly characteristic of the operational closure associated with noise objects (Nunes, 2012, p.100) and forces the viewer to question the ways information is relayed through memes. 
To understand the significance of trends in memetic redundancy, popularly known as 'anti-memes', I first conceived of reaction memes as highly entropic. Entropic messages are characterized by a high level of unpredictable information, and trend towards decay (Shannon, 1948). The unexpected image and text combinations in reaction memes produce high visceral reactions and readily efface their channel. In contrast, anti-memes are highly redundant and ensure the predictability of the message received; highlighting the existence of the channel in the process. This anti-meme logic is repeatedly demonstrated throughout the corpus and consists of such examples as memes bearing the phrases "If I've been distant lately l'm sorry it's because l've Been distant lately" or "Ariana Grande is called 'Ariana Grande' because her first name is Ariana and her last name is Grande" (esoteric_queen, 2017; grapejuiceboys, 2018).

To conclude, I synthesize an understanding of deep-fried memeing as an art practice that adheres to Menkman's notion of 'post-procedural glitch art' $(2011$, p. 38). These artworks, infused with intentional failure of a digital system, produce befuddling and repellent results as a means of interrogating established aesthetic norms (Menkman, 2011, p.38; Contreras-Kotterbay \& Mirocha, 2016, p.149). They speak to a spaciotemporal sensibility that is entirely preoccupied by the ever-present threats of acceleration and accident (Contreras-Koterbay \& Mirocha, 2016, p. 13), which it not only accepts but displays boldly. Deep-fry perhaps best embodies a cubist moment in meme-ing. We know that the canvas is flat, so to speak, therefore which creative possibilities present themselves now that this has been acknowledged?

\section{References}

Barthes, Roland. "The Rhetoric of the Image." In Image-Music-Text, translated by Heath, Stephen, 32-51. New York: Hill and Wang, 1977.

Contreras-Koterbay, Scott, and Łukasz Mirocha. The New Aesthetic and Art:

Constellations of the Postdigital. Theory on Demand. Amsterdam: Institute of Network Cultures, 2016.

esoteric_queen. (2017, November 12). Sometimes it just be like that. [Instagram post]. Retrieved from https://www.instagram.com/p/BbY1scGABGv

grapejuiceboys. (2018, June 18) Incase you wanted to know. [Instagram post].

Retrieved from 


\section{https://www.instagram.com/p/BkMPU00FzyuVeenK9YBh6B0781TMVYQNLIluDA}

$\underline{0}$

Menkman, Rosa. The Glitch Moment(Um). Network Notebook 4. Amsterdam: Institute of Network Cultures, 2011.

Milner, Ryan M. The World Made Meme: Public Conversations and Participatory Media. The Information Society Series. Cambridge, Massachusetts: The MIT Press, 2016.

Miltner, Kate M. “There's No Place for Lulz on LOLCats': The Role of Genre, Gender, and Group Identity in the Interpretation and Enjoyment of an Internet Meme." First Monday 19, no. 8 (August 1, 2014). http://firstmonday.org/ojs/index.php/fm/article/view/5391.

Phillips, Whitney, and Ryan M Milner. The Ambivalent Internet: Mischief, Oddity, and Antagonism Online. Wiley, 2017.

Nunes, M. (2012). Seductive Errors. In X. Burrough (Ed.), Net works: case studies in Web art and design (pp. 100-102). New York; London: Routledge.

Shifman, Limor. Memes in Digital Culture. Boca Raton; London: CRC Press, 2015.

Steyerl, Hito, and Franco Berardi. "In Defence of the Poor Image." In The Wretched of the Screen, 31-45. E-Flux Journal. Berlin: Sternberg Press, 2012. 